\title{
Use of Vernonia polyanthes on Treatment of Inflammatory Illnesses
}

\author{
Alves ASS ${ }^{1}$, Nascimento $\mathrm{CCHC}^{1}$, Stephens $\mathrm{PRS}^{3}$, Saranraj ${ }^{4}$, Barreto $\mathrm{AS}^{1}$ and Diré GF ${ }^{1,2 *}$ \\ ${ }^{1}$ Laboratory of Chemical and Biological Analysis (LAQB), Foundation State University Center of the West Zone (UEZO), Avenue Manuel \\ Caldeira de Alvarenga, 1203, Campo Grande, Rio de Janeiro, 23070-200, Brazil \\ ${ }^{2}$ Estácio de Sá University (UNESA), Rio De Janeiro, Brazil \\ ${ }^{3}$ Laboratory of Innovations in Therapies, Teaching and Bioproducts/ LITEB, Oswaldo Cruz Insti-tute, IOC/ FIOCRUZ) \\ ${ }^{4}$ Department of Microbiology, Sacred Heart College (Autonomous), Tirupattur, Tami Nadu, India \\ *Corresponding author: Diré GF, Laboratory of Chemical and Biological Analysis (LAQB), Foundation State University Center of the \\ West Zone (UEZO), Avenue Manuel Caldeira de Alvarenga, 1203, Campo Grande, Rio de Janeiro, 23070-200, Estácio de Sá University \\ (UNESA), Rio De Janeiro, Brazil
}

\begin{abstract}
Medicinal plants are highly effective alternatives therapies for multiple diseases and are also more accessible to most individuals. Some medications are too expensive and, sometimes, are not available through all national territory. Therefore, a literature review was made aiming to demonstrate the potential of Vernonia polyanthes on the treatment of inflammatory diseases, highlighting even more the important role of the Brazilian flora on life quality of Brazilians. Studies evaluating the action of different extracts of the plant on different inflammatory response models and the results showed inhibition of inflammation at the tested models. The antiinflammatory action is related to components present in the extracts, with some of their inhibition mechanisms known and others to be described. From the characterization of the component molecules of the Vernonia polyanthes extracts, it will be possible to use it in the formulation of drugs and therapies against inflammatory diseases.
\end{abstract}

Keywords: Vernonia polyanthes; assa-peixe; phytotherapy; anti-inflammatory; flavonoids

\section{Introduction}

Using plants with therapeutic properties to treat illnesses is as old as mankind's history. As each generation found out about new species to treat new symptoms, new knowledge was passed through the population and to the next generations. And scientific advance came up with a field of research that evaluated and determined scientifically the medicinal properties of plants and their interactions with the human body. Only in Brazil, 55 thousand species were cataloged, out of a 350 to 550 thousand estimated total. But despite that, in the last decades the number of information about medicinal plants grew only $8 \%$ per year, which is below the expected for the most biodiverse country in the world [1].From these studies, public policies about the using of herbal medicine in basic health begun to be made in order to regulate the use of such plants. The formal use of the popular knowledge of herbal medicines, now scientifically attested, by the Brazilian Single Health System (SUS) was considered one of the most outstanding events of the millennium in public health [2]. An ordinance number 3.916, from October $30^{\text {th }}$ of 1998 , approved the National Medicaments Policy, which assures "support to research that aim the best use of the therapeutic potential of national flora and fauna, emphasizing the certification of their medicative properties" [3].

The Asteraceae family represents well the Brazilian biodiversity. It is represented by approximately 1.900 species, spread through the different biomes of the country [4]. Because of the variety of species, multiple plants of the family stand out for their curative properties, like the Lychnophora, Mikania and the Baccharis genus, the last being used on the treatment of diabetes and gastroenteritis [5]. Another genus that stands out for its therapeutic role is the Vernonia, with approximately 1.000 species throughout the world but with a preference for tropical climates [6]. Antibacterial and antitumoral actions are the most attributed to them [7]. Vernonia polyanthes or "Assa-Peixe", as it's known popularly, is a 3 to 9 -foot 
bush with simple leaves and white flowers. It is found at roadsides and wastelands and it's an important font of nectar for honeybees [8]. According to Rodrigues KC [9], it is used as diuretic, antihypertensive, antiulcer,and evenonthetreatmentofmalariaandfever.

\section{Methodology}

The gathering of literature for review was made through academic paper banks online, such as PubMed, Scholar Google and SCIELO, using as keywords: "Vernonia polyanthes", "Vernonia" and "Asteraceae". Other than scientific articles and academic papers, official documents from Brazilian government were obtained through regular search mechanisms, like Google, using "medicinal plants" or "phytotherapy" as keywords.

\section{Discussion}

Vernonia polyanthes is an old friend of alternative medicine and popular knowledge of native populations of Brazil. Therefore, it is being targeted by studies aiming to confirm its pharmacological efficacy, making possible to introduce it as a viable alternative of treatment for multiple diseases. In recent years, its antiinflammatory action is being evaluated. Temponi VS et al. [10] evaluated the antinociceptive properties associated to the antiinflammatory role, using different in vivo tests with male albino mice. The first test conducted was the abdominal contortions test, which counts the abdominal torsions of the animal followed by torso torsions and hind limbs extension, caused by the pain of an inflammatory response induced by acetic acid injections on peritoneum [11].

On the test, the animals were previously treated with different dilutions of etanolic extract of Vernonia polyanthes leaves (100, 200 and $400 \mathrm{mg} / \mathrm{kg}$ ) an hour before the intraperitoneal injection of acetic acid $0,6 \% \mathrm{v} / \mathrm{v}$. Ten minutes after the injection the contortions begun to be counted, during a period of 20 minutes. The percentage of inhibition of abdominal contortions previously treated with the extract were, respectively, 2,64\%, 16,75\% and 31,44\%, showing that it was effective to reduce inflammatory response and the inhibition is proportional to the concentration of the extract.

Another test conducted was the carrageenan induced pleurisy. The mice were divided in groups, anesthetized and treated with indomethacin, dimethyl sulfoxide $1 \%$ or ethanolic extract of 100 , 200 or $400 \mathrm{mg} / \mathrm{kg}, 60$ minutes before the injection of irritant agent into the pleural cavity. After $4 \mathrm{~h}$ from the carrageenan injection the mice were killed, and the exudate was collected from the area of the injection to perform leucocyte counting. The $200 \mathrm{mg} / \mathrm{kg}$ dose was able to inhibit the leucocyte counting in $17,87 \%$ and reduced the exudate volume in $13,83 \%$, in comparison with untreated group. Similarly, the $400 \mathrm{mg} / \mathrm{kg}$ dose inhibited $28,39 \%$ the number of leucocytes and $43,08 \%$ the exudate volume. With other similar tests conducted, the study showed that the ethanolic extract of Vernonia polyanthes has showed significative anti-inflammatory and anti-nociceptive effects [10].

Another study, conducted by Rodrigues et al. [9], evaluated the topic anti-inflammatory effect of hexane (HEVP) and ethyl acetate (EAEVP) extract from Assa-Peixe's leaves. In this study were performed ear edema induction tests on swiss albino mice. In the ear edema induction by croton oil test, $20 \mu \mathrm{L}$ of oil was applied inside the right ear of the mice. After 15 minutes, they applied HEVP, EAEVP (0,1, 0,5 and 1mg/ear), or dexamethasone (positive control, $0,1 \mathrm{mg} /$ ear). The negative control was made by applying acetone on the left ear. The edema was evaluated after 6 hours from the oil application, through weighting and histopathological analysis from $6 \mathrm{~mm}$ ear samples.

EAEVP showed inhibition of $28 \%, 37 \%$ and $37 \%$ of the tissue samples at the doses of $0,1,0,5$ and $1 \mathrm{mg} /$ ear, while HEVP was able to inhibit $58 \%, 48 \%$ and $37 \%$ at the same doses. Histopathological analysis showed inhibition of edema of $58,7 \%, 50,3 \%$ and $37,6 \%$ to 0,1, 0,5 and $1 \mathrm{mg} /$ ear HEVP doses, and of $19,9 \%, 22,8 \%$ and $23 \%$ of the same doses of EAEVP. Furthermore, there was reduction of vasodilation and leucocyte migration on the observed tissue. Hexane extracts were more effective inhibiting edema, although its action was not dose dependent.

Both studies associated the anti-inflammatory activity of the extracts to the presence of chemical components, mainly flavonoids such as luteolin, apigenin and rutin. It was already reported that the anti-inflammatory activity of rutin is due the inhibition of pro-inflammatory cytokines, which reduce the recruitment and activation of neutrophils to inflammation site [12]. A study conducted by Funakoshi-Tago $\mathrm{M}$ et al. [13] the anti-inflammatory action of apigenin, luteolin and fisetin, which are structurally similar, showed that apigenin and luteolin are effective on inhibiting transcriptional activity of NF-kB p65, an important factor on inflammatory responses. Identification of existing compounds on Vernonia polyanthes and its anti-inflammatory effects open way to the development of drugs to treat inflammatory illnesses.

\section{Conclusion}

Using plant-derived extracts as therapy, despite not being new, has never been so necessary as today, especially with native species and accessible for most of the population, if not to all. The Vernonia genus has multiple species that are easily found throughout Brazilian territory and has multiple therapeutic properties attributed to them. Recent studies evaluating the anti-inflammatory activity of Vernonia polyanthes showed promising results to the development of new therapies using its extracts. The ethanolic extract showed itself to be an effective analgesic and anti-inflammatory, inhibiting abdominal contortions in mice, reducing leucocyte migration to the inflammation site and the exudate volume. Hexane and ethyl acetate also attested its action by inhibiting edema, which is one of inflammation's cardinal signs.

Superficial analysis of extracts composition showed the mainly components responsible for its anti-inflammatory action, such as rutin, apigenin and luteolin, but their ways of acting are yet to be fully known. A more detailed characterization of the composition of the Vernonia polyanthes extracts can lead to identification of new compounds with important roles to inhibit inflammation and that may become helpful on the development of anti-inflammatory drugs. 


\section{Acknowledgement}

We thank the Foundation for Research Support of the State of Rio de Janeiro (FAPERJ), for the support to the research carried out in the Laboratory of Chemical and Biological Analysis (LAQB) of the Foundation State University Center of the West Zone (UEZO).

\section{References}

1. Minas G (2012) Epamig researches production of medicinal plants for application in SUS. DIA de CAMPO.

2. Claudia AAF (2006) Phytotherapy in SUS and the medicinal plant research program of the medicines center. Brasília: Basic Health Texts, Printing and Publishing Ideal Ltd, Brazil, pp. 148.

3. Brazil Constitution (1998) Ordinance No. 3916, of October 30. Brasília, Brazil.

4. Roque N, Bautista H (2008) Asteraceae: characterization and floral morphology. EDUFBA, Salvador, Brazil, p. 73.

5. Carvalho CC, Machado KN, Ferreira PMP, Pessoa C, Fonseca THS, et al. (2013) Biological screening of extracts of Brazilian Asteraceae plants. African Journal of Pharmacy and Pharmacology 7(1): 2000-2005.

6. Keeley SC, Jones SB (1979) Distribution of pollen types in Vernonia (Vernonieae: Compositae). Systematic Botany 4(3): 195-202.
7. Jisaka M, Ohigashi H, Takegawa K, Huffman MA, Koshimizu K (1993) Antitumoral and antimicrobial activities of bitter sesquiterpene lactones of Vernonia amygdalina, a possible medicinal plant used by wild chimpanzees. Biosci Biotech Biochem 57(5): 833-834.

8. Ramos, Oliveira J (2014) Evaluation of toxic activity and phytochemical profile of extracts and fractions of Vernonia Condensata baker and Vernonia Polyanthes less. Federal Institute of Education, Science and Technology of Goiás, Anápolis, Brazil.

9. Rodrigues KC, Chibli LA, Santos BC, Temponi VS, Pinto NC, et al. (2016) Evidence of bioactive compounds from Vernonia Polyanthes leaves with topical anti-inflammatory potential. Int J Mol Sci 17(12): E1929.

10. Temponi VS, da Silva JB, Alves MS, Ribeiro A, de Jesus RGP, et al. (2012) Antinociceptive and anti-inflammatory effects of ethanol extract from Vernonia Polyanthes leaves in Rodents. Int J Mol Sci 13(3): 3887-3899.

11. Silva JC, de Lima SRGS, de Oliveira RG, da Silva JRGA (2013) Experimental models for antinociceptive activity evaluation of products natural: a review. Rev Bras Farm 94(1): 18-23.

12. Selloum L, Bouriche H, Tigrine C, Boudoukha C (2003) Anti-inflammatory effect of rutin on rat paw edema, and on neutrophils chemotaxis and degranulation. Exp Toxicol Pathol 54(4): 313-318.

13. Funakoshi-Tago M, Nakamura K, Tago K, Mashino T, Kasahara T (2011) Anti-inflammatory activity of structurally related flavonoids, Apigenin, Luteolin and Fisetin. Int Immunopharmacol 11(9): 1150-1159.

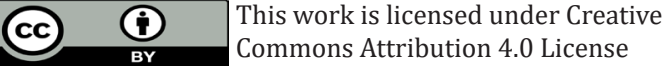

To Submit Your Article Click Here: Submit Article

DOI: $10.32474 /$ CTBM.2020.01.000119

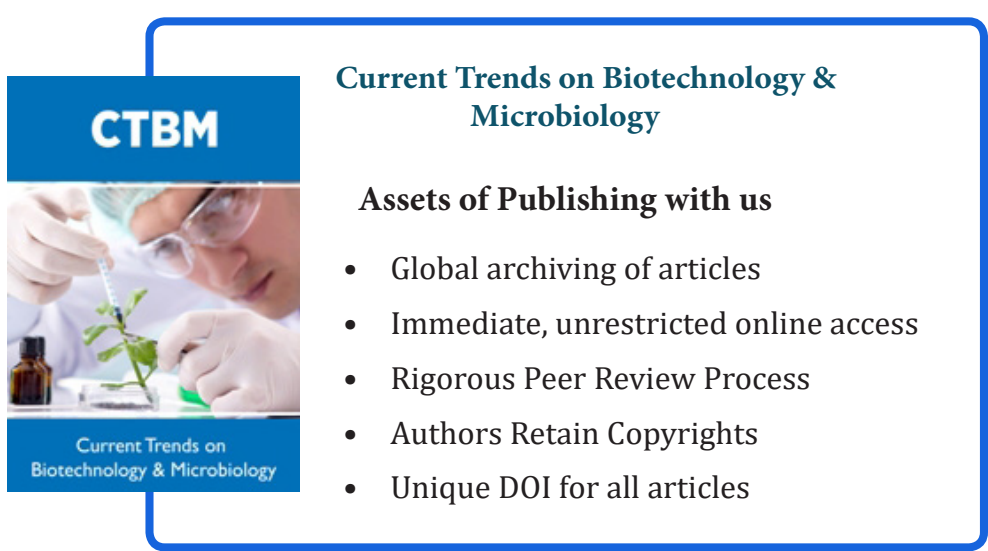

